\title{
Metoclopramide in gastrooesophageal reflux
}

\author{
C. STANCIU AND JOHN R. BENNETT \\ From the Gastrointestinal Unit, Hull Royal Infirmary
}

SUMMARY In 30 patients with gastrooesophageal reflux, intravenous metoclopramide (Maxolon) has been shown to increase the gastrooesophageal sphincter pressure. The rise is dose-related until a maximum pressure, proportional to the resting sphincter tone, is reached. The effect is reversed by atropine. Peristaltic waves are increased in pressure by metoclopramide.

In 18 patients with gastrooesophageal reflux intravenous metoclopramide diminished the frequency of reflux episodes and increased the rate at which the oesophagus emptied itself of an acid load.

Metoclopramide (Maxolon) has been shown to have a number of actions on gastrointestinal motility but little attention has been paid to its effects on the oesophagus. The one detailed study published (Heitmann and Möller, 1970) clearly demonstrates that in healthy adults the drug raises the pressure of the gastrooesophageal sphincter and increases the height and duration of peristaltic contractions in the distal oesophagus. An obvious potential application of these actions is to prevent gastrooesophageal reflux, and we have studied its effect in patients with symptoms of 'reflux oesophagitis'.

\section{Apparatus}

Intraluminal pressures were recorded through two polyethylene catheters (internal diameter $1.2 \mathrm{~mm}$ ) each with a single side hole, the openings being set $5 \mathrm{~cm}$ apart. The catheters were continuously perfused with distilled water at $0.8 \mathrm{ml} / \mathrm{min}$ by a constant infusion syringe pump and were connected to Bell and Howell transducers.

Intraluminal $\mathrm{pH}$ was measured by a Radiometer combined glass and reference electrode (GK 282C) with Radiometer pH meter (type PHM 26) which was standardized before each test. The output of transducers and $\mathrm{pH}$ meter was recorded on a Devices M 19 multichannel direct writing recorder. Respiration was recorded by a belt pneumograph.

\section{The Effect of Metoclopramide on Gastro- oesophageal Motility}

\section{METHODS}

Gastrooesophageal sphincter pressures were studied Received for publication 12 January 1973. in 16 men and 14 women aged 18 to 77 years (mean 51.2 years) with symptoms of gastrooesophageal reflux (heartburn, acid regurgitation, and discomfort on drinking hot fluids). Radiologically eight had been shown to have a hiatus hernia and 11 gastrooesophageal reflux, and all had abnormal gastrooesophageal reflux detected by 15-hour intraoesophageal pH recordings (Stanciu and Bennett, to be published). Three patients had previously had truncal vagotomy and pyloroplasty for duodenal ulceration.

Recordings were made with the patients supine by withdrawing the previously swallowed tube assembly from the stomach to oesophagus in $0.5 \mathrm{~cm}$ steps. At each point in the oesophagus, pressures were recorded both during quiet breathing and during swallows. In 20 patients the procedure was repeated after the intravenous injection of $5 \mathrm{ml} 0.9 \%$ sodium chloride solution, and again after $10 \mathrm{mg}$ metoclopramide intravenously. The patients were not aware which injection contained the drug, but had previously given consent to the study.

In another 10 patients the solutions were given by continuous intravenous infusion while the distal catheter opening was held in the gastrooesophageal sphincter. At first, $0.9 \%$ sodium chloride was infused and then metoclopramide $(40 \mathrm{mg} / 100 \mathrm{ml}$ saline) at increasing rates. The infusion was continued at each rate for five to six minutes. In six of these patients atropine $(0.3 \mathrm{mg} / \mathrm{kg})$ was given intravenously at the end of the metoclopramide infusion.

\section{RESULTS}

The mean resting end-expiratory gastrooesophageal sphincter pressure (average of recorded pressure in all patients) before metoclopramide was $11.8 \pm \mathrm{SD}$ $5.7 \mathrm{~cm}$ water. There was no significant change after 

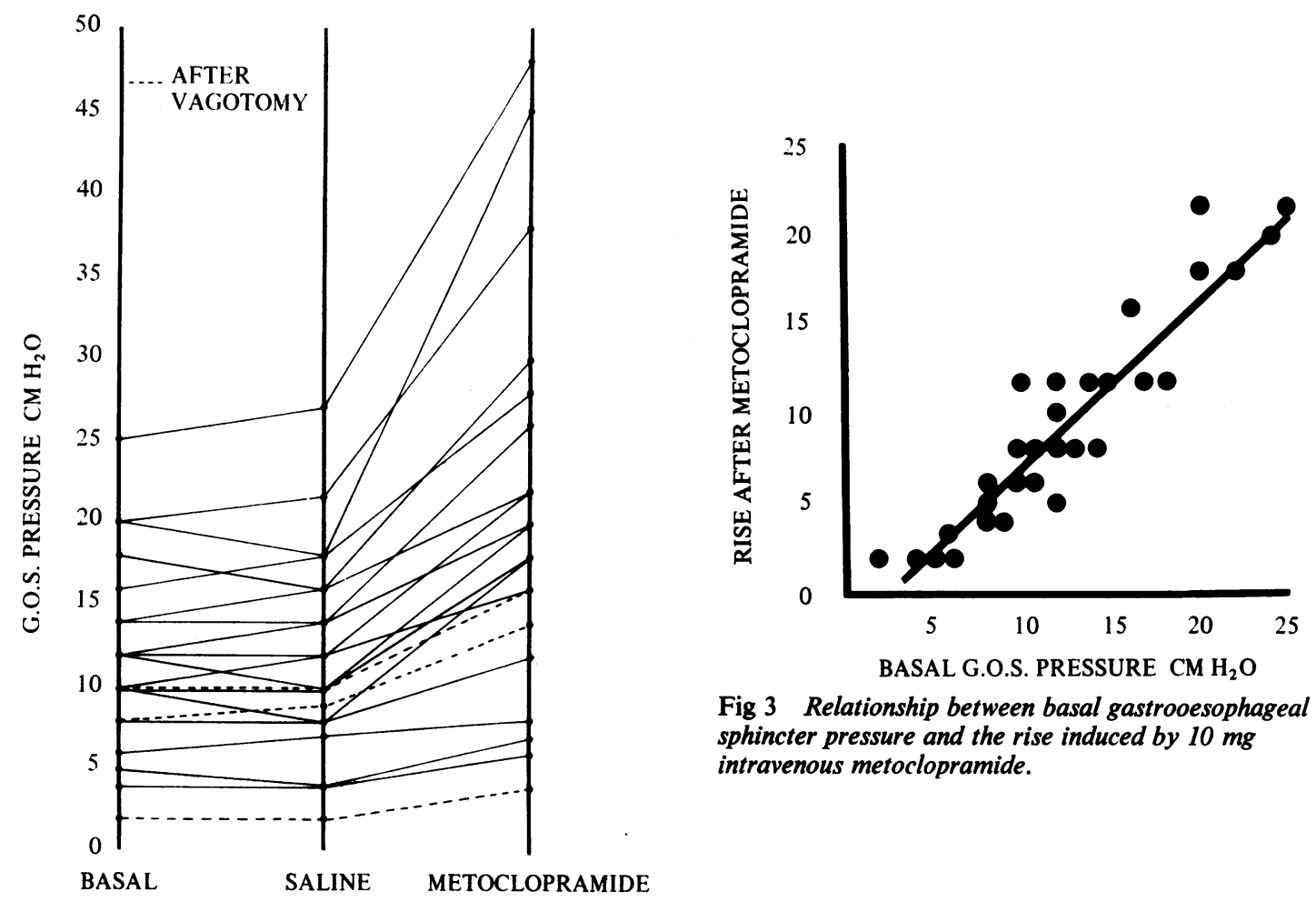

Fig 3 Relationship between basal gastrooesophageal sphincter pressure and the rise induced by $10 \mathrm{mg}$ intravenous metoclopramide.

Fig 1 Change in gastrooesophageal sphincter pressure induced by intravenous injections of normal saline or $10 \mathrm{mg}$ metoclopramide.
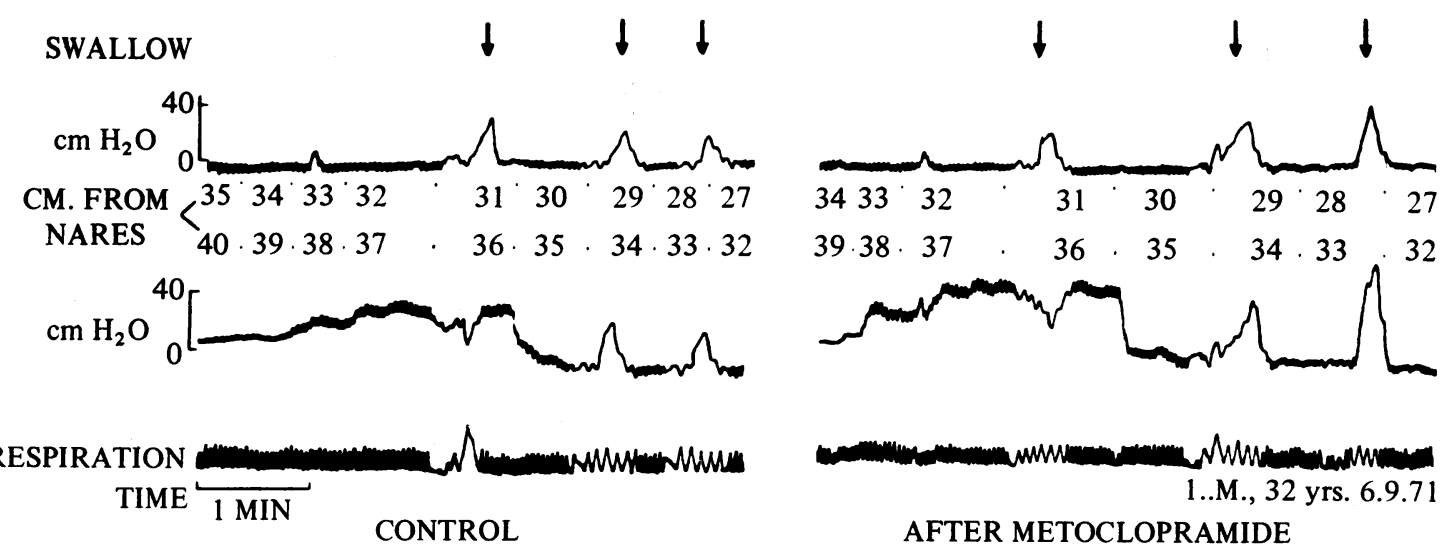

Fig 2 Recording of intraluminal pressures, from perfused open-tip tubes $5 \mathrm{~cm}$ apart, during withdrawal in the same patient before and after metoclopramide, $10 \mathrm{mg}$. The 'pressure profile' of the gastrooesophageal sphincter is shown in the middle trace. After metoclopramide the peak sphincter pressure rises but relaxation on swallowing is unimpaired. The upper trace demonstrates the increased height of peristaltic waves after metoclopramide. 


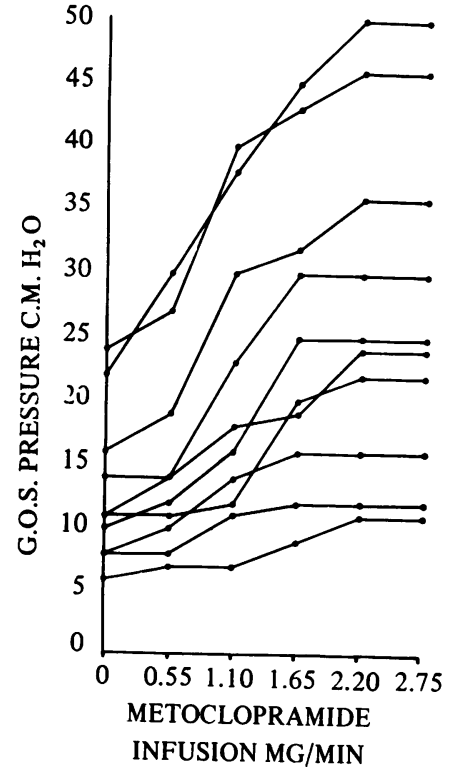

Fig. 4

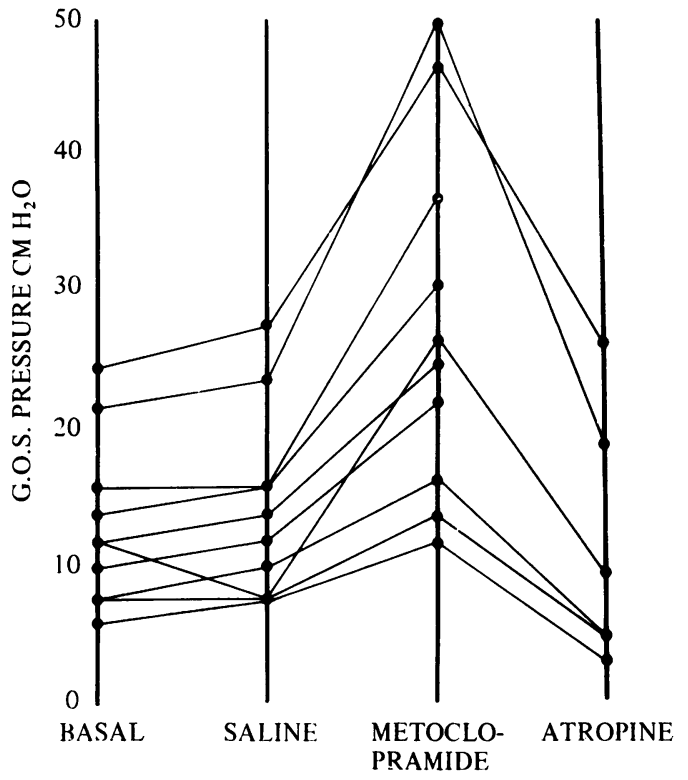

Fig. 5

Fig. 4 Rise of gastrooesophageal sphincter pressure induced by intravenous infusion of metoclopramide $(40 \mathrm{mg} / 100 \mathrm{ml})$ at increasing rates.

Fig. 5 Changes in gastrooesophageal sphincter pressure induced by intravenous infusions of saline and metoclopramide $(2.75 \mathrm{mg} / \mathrm{min})$, and an intravenous injection of atropine $(0.3 \mathrm{mg} / \mathrm{kg})$ immediately after the metoclopramide infusion.

administration of intravenous saline, but intravenous metoclopramide invariably raised the pressure (fig. 1). The mean pressure after metoclopramide was $20.8 \pm 9.7 \mathrm{~cm}$ water, a significant rise $(P<0.01)$. The length of the sphincter did not change, and relaxation on swallowing was unimpaired (fig. 2). The rise induced by $10 \mathrm{mg}$ metoclopramide was from 2 to $23 \mathrm{~cm}$ water and the rise was proportional to the resting pressure (fig. 3). The effects were equally marked in patients after vagotomy. During intravenous infusions at increasing rates the pressure rose within seconds of each increment until it reached a plateau beyond which further increments would not raise it (fig. 4). Atropine produced a marked fall in sphincter pressure, even while the metoclopramide effect was still present, usually reducing it below the resting tone (fig. 5).

Resting pressure in the gastric fundus and in the body of the oesophagus did not change after metoclopramide. However the mean pressure of peristaltic contractions was increased from
$38.7 \pm$ SD $7 \cdot 2$ to $43 \pm 7 \cdot 1 \mathrm{~cm}$ water by metoclopramide $(\mathrm{P}<0.01)$. The duration and speed of propagation of peristaltic waves was increased, but not by significant amounts, and the proportion of synchronous and spontaneous contractions was unchanged.

\section{DISCUSSION}

The precise mechanism of metoclopramide's actions on the gut is not yet determined but its probable direct effects on smooth muscle cells (Hukuhara, Nakayma, Fukuda, and Neya, 1966; Coulland and Levêque, 1966) may be due to increased sensitivity to acetylcholine (Eisner, 1968).

Our observations first confirm those of Heitmann and Möller (1970) in showing a selective increase in lower oesophageal sphincter pressure after intravenous metoclopramide, without altering gastric fundal pressures. We further showed that this effect is dose-related; successive increments in dose raised the pressure until a maximum pressure was reached. 
Both the incremental rises in pressure, and the final maximum 'plateau' pressure, are proportional to the original resting pressure of the sphincter.

Our studies on patients after vagotomy indicate that the effects of metoclopramide on the gastrooesophageal sphincter do not depend on an intact vagus nerve, but the inhibitory action of atropine suggests that it may act via the intramural cholinergic neuromuscular apparatus.

\section{The Effect of Metoclopramide on Gastro- oesophageal Reflux}

\section{METHODS}

Acid clearance was performed in 18 patients (eight men and 10 women, mean age 54.4) and reflux test in 16 patients (seven men and nine women, mean age 52.2) known to have gastrooesophageal reflux, before and after a bolus injection of $10 \mathrm{mg}$ intravenous metoclopramide.

Acid clearance test (Booth, Kemmerer, and Skinner, 1968: Skinner and Booth, 1970)

The electrode was placed $5 \mathrm{~cm}$ above the gastrooesophageal sphincter. The manometric catheters were withdrawn above the electrode, and the continuous perfusion pump was stopped. With the patient supine $15 \mathrm{ml} 0 \cdot 1 \mathrm{~N}$ hydrochloric acid was introduced through the proximal catheter $10 \mathrm{~cm}$ above the electrode, and the patient was instructed to swallow every 30 seconds. The number of swallows necessary to raise the lower oesophageal $\mathrm{pH}$ from 1.5 to 6 was then counted.

\section{Reflux test}

The manometric catheters were introduced into the stomach and $250 \mathrm{ml} 0 \cdot 1 \mathrm{~N}$ hydrochloric acid was instilled. The catheters were flushed with a little water and air and then withdrawn above the $\mathrm{pH}$ electrode. The patient then performed a series of manoeuvres-deep breathing, Valsalva, Muller, coughing - while lying supine, on the right side and on the left side, and supine with $15^{\circ}$ head-down tilt. The pH was recorded continuously $5 \mathrm{~cm}$ above the gastrooesophageal sphincter.

\section{Statistical methods}

Results before and after metoclopramide have been compared by the Wilcoxon matched pair signed rank test.

\section{RESULTS}

Acid clearing (fig. 6)

The mean number of swallows to raise the lower

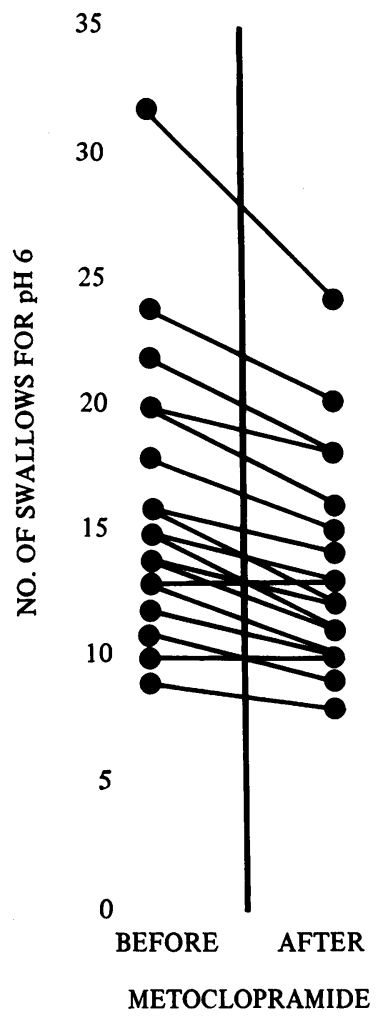

Fig. 6 Acid clearing test results before and after $10 \mathrm{mg}$ intravenous metoclopramide, indicating the number of swallow snecessary to raise intraluminal pH from 1.5 to 6.

oesophageal pH to 6 was $16 \cdot 3 \pm$ SD $5 \cdot 6$ before and $13.5 \pm 4.3$ after metoclopramide. The difference is significant $(P<0.01)$.

\section{Reflux (16 patients)}

Before metoclopramide all patients showed gastrooesophageal reflux after some manoeuvres. After metoclopramide no reflux was detected in six patients. In all the remaining 10 patients the number of manoeuvres which caused reflux was diminished $(P<0.01)$ (fig. 7).

\section{DISCUSSION}

This study shows that metoclopramide has the useful effect, in patients who suffer from gastrooesophageal reflux, of markedly diminishing the frequency of episodes of reflux; moreover it increases the rate at which the oesophagus rids itself of acid contents. The likely methods by which metoclopramide achieves this result were demonstrated in the previous paper. The rise in tone of the lower oesophageal sphincter presumably assists in 


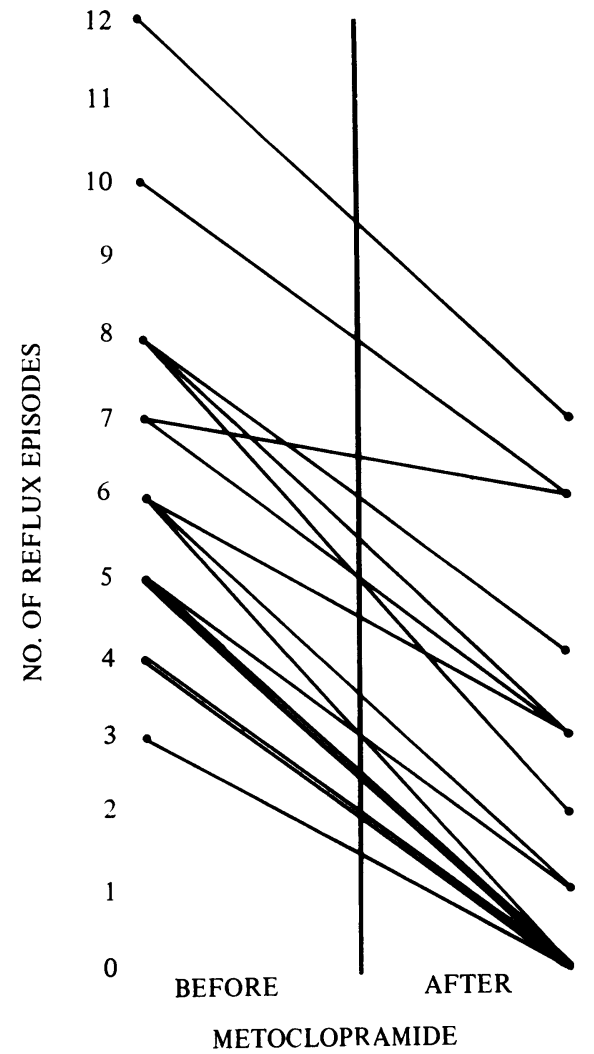

Fig. 7 Number of reflux episodes during standard manoeuvres before and after $10 \mathrm{mg}$ intravenous metoclopramide.

preventing reflux, while the increased pressure of peristaltic contractions may assist oesophageal emptying. Our findings conflict with those of Glanville and Walls (1972) who, using standard radiological techniques, found that intravenous metoclopramide failed to change the incidence of gastrooesophageal reflux during barium meal examinations. The reason for the difference probably lies in the methodology. Radiology has been shown to be an imprecise tool for demonstrating gastrooesophageal reflux (Piccone, Gutelius, and McCorriston, 1965; Skinner and Booth, 1970); short-term changes in degree of reflux require more sensitive techniques for their demonstration.

Our results are all in short-term experiments using intravenous administration. It remains to be shown whether metoclopramide, given regularly by mouth, is equally effective, and studies to demonstrate this are in progress.

The nursing staff of the Hull Royal Infirmary Gastrointestinal Unit gave great assistance in caring for the patients.

Beecham's Laboratories Ltd generously contributed the Maxolon used in the study. The invaluable technical help of Mr J. Holman was financed by the Wellcome Foundation. Carol Stanciu is the recipient of a research grant from the Leeds Regional Hospital Board.

References

Booth, D. J., Kemmerer, W. T., and Skinner, D. B. (1968). Acid clearing from the distal esophagus. Arch. Surg., 731-34, 96.

Coulland, D., and Levêque, J. (1966). Action du métaclopramide sur différentes portions de l'intestin isolé de lapin, et sur l'intestin 'in situ.' Path. et Biol., 14, 963-965.

Eisner, M. (1968). Gastrointestinal effects of metoclopramide in man. In vitro experiments with human smooth muscle preparations. Brit. Med. J., 4, 679-680.

Glanville, J. N., and Walls, W. D. (1972). Effect of intravenous metoclopramide on gastrooesophageal reflux. Gut, 13, 31-32.

Heitmann, P., and Möller, N. (1970). The effect of metoclopramide on the gastroesophageal junctional zone and the distal esophagus in man. Scand. J. Gastroent., 5, 620-626.

Hukuhara, T., Nakayma, S., Fukuda, H., and Neya, T. (1966). Mechanism of metoclopramide on the intestinal movements. Jap. J. Smooth Muscle Res., 2, 22.

Piccone, V. A., Gutelius, J. R., and McCorriston, J. R. (1965). A multiphased esophageal pH test for gastroesophageal reflux. Surgery, 57, 638-646.

Skinner, D. B., and Booth, D. J. (1970). Assessment of distal esophageal function in patients with hiatal hernia and/or gastroesophageal reflux. Ann. Surg., 172, 627-637. 